\title{
A Study of Energy Intensity and Carbon Intensity from Olefin Plants in Thailand
}

\author{
Wasamon Chuapet ${ }^{1}$, Nantamol Limphitakphong ${ }^{2}$, Thanapol Tantisattayakul ${ }^{3}$, Premrudee Kanchanapiya ${ }^{4}$ and Orathai \\ Chavalparit $^{1,2}$ \\ ${ }^{1}$ Department of Environmental Engineering, Faculty of Engineering, Chulalongkorn University, Bangkok, 10330, Thailand \\ ${ }^{2}$ Research unit of Environmental Management and Sustainable Industry, Faculty of Engineering, Chulalongkorn University, Bangkok \\ 10330, Thailand \\ ${ }^{3}$ Faculty of Science and Technology, Thammasat University Rangsit Campus, Pathumthani, 12121, Thailand \\ ${ }^{4}$ National Metal and Materials Technology Center, 114 Thailand Science Park, Pathumthani, 12120, Thailand
}

\begin{abstract}
This research is aimed to estimate energy consumption and the greenhouse gases emission from olefins production process in Thailand and to analysis its correlation between energy intensity and carbon intensity. The results of five olefin case study plants showed that direct energy use of olefins production was about $87 \%$ of total energy consumption. The greatest amount of energy demand was supplied for fuel combustion in manufacturing processes. The olefin plants using gas feedstock could operate with less amount of energy consumed as the average energy intensity (EI) of $23.88 \mathrm{GJ} /$ ton of olefin produced, whereas plants of olefin produced from steam cracking of liquid feedstock had the average EI of $33.21 \mathrm{GJ} /$ ton of olefin produced. Greenhouse gas emission from olefin plants using gas feedstock were consistent with the result of EI. The carbon intensity (CI) from olefin plants using gas feedstock $\left(0.98 \mathrm{tCO}_{2}\right.$-eq./ton of olefin produced) was lower than the plants using liquid feedstock $\left(2.01 \mathrm{tCO}_{2}\right.$-eq./ton of olefin produced). The T-test function used to reflect the correlation between EI and CI emphasized that the carbon intensity was significantly correlated with the intensity of energy $(r=0.9564$ and $p=0.05)$.
\end{abstract}

\section{Introduction}

The main cause of global warming is the emission of greenhouse gases from industry sector [1], mainly due to burning fossil fuels to produce energy and products. As a result of climate change at the global scale, changes in both physical and biological system [2] regarded as a major issue in all regions have been concerning very closely as seen from The twenty-first session of the Conference of the Parties (COP21) in Paris (2015 United Nations Climate Change Conference, COP21). The goal of limiting the average global temperature not to exceed 2 degrees Celsius from pre-industrial levels was agreed by 195 nations through the cooperation action and funding from developed countries to encourage stronger action by developing countries [3]. IEA states that the industry sector requires high energy use and emit a great amount of greenhouse gases. In 2005, the proportion of global energy consumption from industry sector was up to $33 \%$ of total final energy consumption particularly in petrochemical industry about $34 \mathrm{EJ}$ [4]. The proportion of greenhouse gas emissions from industry sector was accounted for $21 \%$ of total global emissions, whereas $23 \%$ of that emissions contributed from petrochemical industry [5] due to the industrial use of fuel oil and natural gas as raw material and fuel in the production process. In 2006 furthermore, the demand of energy and raw materials in petrochemical industry was about $10 \%$ of total global final energy consumption, representing 30\% of total final energy consumption in the industry sector [6].

Upstream petrochemical industry is the industry that produces three product groups including alkane group, olefin group, and aromatic group. Main product of the upstream industry is olefin group, including ethylene, propylene, mixed-C4, butadiene and butene-1. These products are used as raw materials for intermediate and downstream petrochemical industry. For example, ethylene is the feedstock for Polyethylene plastic beads such as low density polyethylene (LDPE) and high density polyethylene (HDPE), propylene is used in manufacturing of polypropylene (PP) plastic beads which is the downstream petrochemical products used in producing plastic items such as food-containing clear plastic bags and films [7].

In Thailand, the petrochemical industry normally uses steam cracking of gas feedstock (e.g., ethane and propane) or of liquid feedstock (e.g., naphtha). This process, mostly used worldwide currently, consists of the 'cracking furnace' which is the first unit drawing feedstock such as ethane gas, naphtha, LPG, propane, butane or mixed raw material into the cracking process 
obtaining compounds with smaller molecules. Then, the furnace transfers these materials to the temperaturereducing and pressure-increasing unit which are the two most energy-consuming units. From these two units, the materials are then transferred to heat exchanger and separated into a variety of petrochemical products and byproducts [6]. This process consumes energy approximately 2-3 EJ with the amount of the greenhouse gas emissions approximately $180-200 \mathrm{ktCO}_{2}$-eq. [8].

There are some previous studies on olefin production. For example, steam cracking of ethane in U.S. required energy about $23.50 \mathrm{GJ} /$ ton and emitted the greenhouse gas emissions by $0.90 \mathrm{tCO}_{2}$-eq./ton of ethylene [9-10]. For the production using naphtha as feedstock, the energy demand was approximately $31.5 \mathrm{GJ} /$ ton and greenhouse gas emissions by $2.47 \mathrm{tCO}_{2}$ emission/ton of ethylene [9, $11]$.

Studying mitigation options to reduce energy consumption and greenhouse gas emissions is important to help untie global problems. IEA reported that industry sector can reduce either the energy consumption (25-37 $\mathrm{EJ} / \mathrm{year})$ or greenhouse gas emissions (1.9-3.2 $\mathrm{GtCO}_{2}$ /year) by improving energy efficiency or using best practices technology [4]. Whether implementation of best available technologies energy efficiency measures, switching to fuels with low carbon element and recycling materials to reduce direct greenhouse gas emission in 2050 was approximately $30 \%$ [12].

The main objective of this study was to evaluate the energy consumption in term of energy intensity and greenhouse gas emission in term of carbon intensity from the olefin production process in Thailand. An influence of different feedstock or fuel on energy intensity (EI) and carbon intensity $(\mathrm{CI})$ was discussed. The findings of this study would be an alternative approach leading to achieving the global goal of reducing greenhouse gas emissions as one of the solution of global warming.

\section{Methodology}

This study is divided into two sections; the assessment of EI and CI from the olefin production process using different feedstock types and their correlation. Annual data of 2012-2014 were collected from five olefin plants to represent olefins manufacturing of Thailand. The scope of work was focused only on olefin production processes as shown in Figure 1.

\subsection{Olefin plant case studies}

According to collected data, five olefin plants in Thailand could be divided into two groups by type of feedstock; the first two plants using gas feedstock and the last three plants operating with liquid feedstock. Description of feedstock and fuel types each plants is shown in Table 1.

\subsection{Energy consumption and energy intensity}

The estimation of needed amount of energy consumption in olefin production process is divided into 2 parts; direct and indirect energy, which total energy consumption can be calculated by equation (1) as follows;

$$
E C=E C_{\text {Direct }}+E C_{\text {Indirect }}
$$

where $E C$ is the total energy consumption for olefin process $(\mathrm{GJ}), E C_{\text {Direct }}$ is the needed amount of energy the needed amount of energy indirectly consumed in the process (GJ).

Table 1. Feedstock and fuel types of olefin production plants

\begin{tabular}{cccccc}
\hline Olefin Plant & $\mathbf{1}$ & $\mathbf{2}$ & $\mathbf{3}$ & $\mathbf{4}$ & $\mathbf{5}$ \\
\hline $\begin{array}{c}\text { Feedstock } \\
\text { type } \\
\text { (G:L) }\end{array}$ & $100: 0$ & $100: 0$ & $70: 30$ & $20: 80$ & $0: 100$ \\
\hline
\end{tabular}

Fuel used for
direct

$\begin{array}{cccccc}\begin{array}{c}\text { direct } \\ \text { consumption }\end{array} \quad 100: 0 & 90: 10 & 100: 0 & 100: 0 & 80: 20\end{array}$

(FG:FO)

Note : $\mathrm{G}$ is Gas feedstock (i.e. Ethane)

$\mathrm{L}$ is Liquid feedstock (i.e. Naphtha)

FG is Fuel gas

FO is Fuel oil

The direct energy means the energy obtained by burning fuel in the manufacturing process such as fuel gas and fuel oil, while the indirect energy refers to the use of electricity and steam in the process. Both of that can be calculated by the equation (2) as follows;

$$
E C_{\text {Direct/Indirect }}=\sum(F A \times N V C)
$$

where $E C_{\text {Direct/Indirect }}$ is the amount of direct/indirect energy (GJ), $F A$ is the quantity of energy (unit) and $N V C$ is the net calorific value of fuel type (GJ/unit)

The assessment of the needed amount of energy consumption is presented in terms of energy intensity, which refers the needed amount of energy consumption in one unit manufacture as expression in equation (3);

$$
E I=E C / P
$$

where $E I$ is the energy intensity of olefins $(\mathrm{GJ} /$ ton of olefin produced), $E C$ is the total annual energy consumption for the production process (GJ/year) and $P$ is the total amount of olefin produced a year (ton of olefin produced /year)

\subsection{Greenhouse gas emissions and carbon intensity}

For estimating the amount of greenhouse gas emission from the olefin production process, three greenhouse gases; carbon dioxide, methane and nitrous oxide are mentioned. The calculation in this section refers to IPCC (2006) [13] and API (2009) [14] guidelines. To clearly identify the emission sources, two key issues are separately considered; direct and indirect emissions. According to Figure 1, direct emission refer to the 
emissions from carbon dioxide separation from gas feedstock (1), de-carbonization in the furnace (2), fuel combustion (3), methane leaking from olefin production process, fugitive, water treatment (4), and flare (5), whilst indirect emission means the emission related to consuming indirect energy (6).

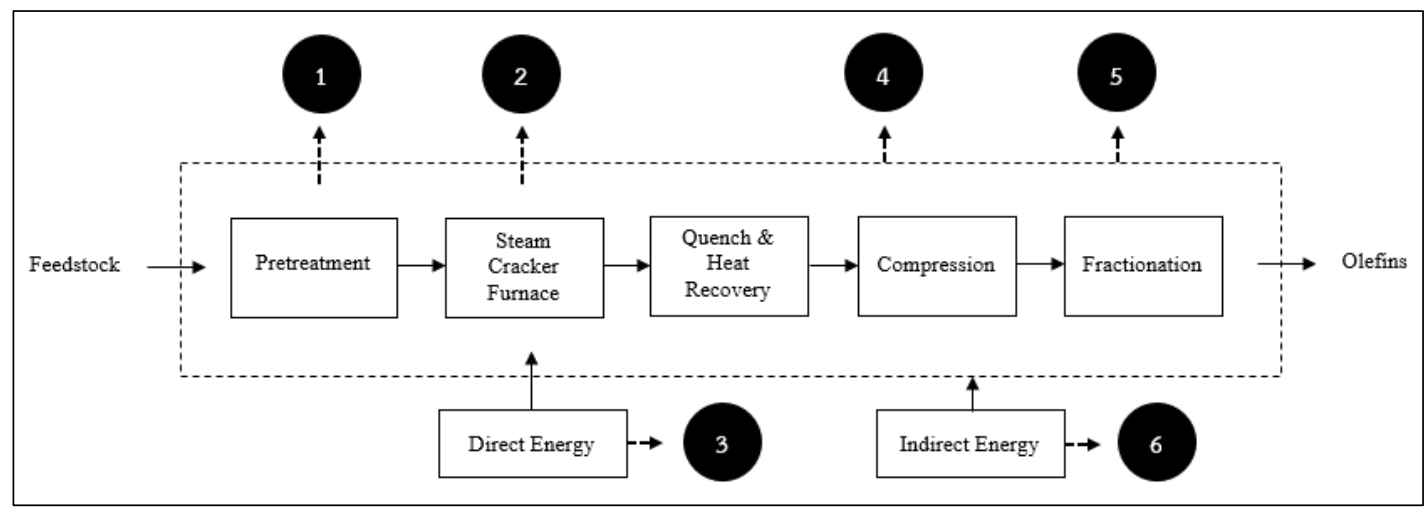

Figure 1. Olefin production flow.

The amount of greenhouse gases emitted by in each particular activities can be calculated by the equation (4) and (5) as follow;

$$
G H G_{\text {Emission }}=A D \times E F
$$

where $G H G_{\text {Emission }}$ is the amount of greenhouse gases emitted from all activities ( $\mathrm{t} G H G$ ), $A D$ is the activity data of relevant olefin production process (unit) and $E F$ is an emission factor of greenhouse gas emissions ( $\mathrm{t}$ GHG/unit), by using the value obtained from the manufacturing plants. In case of the EF is unavailable from the plants, the value will be taken from IPCC (2006) [13].

$$
E_{\mathrm{CO}_{2} \text { eq. }}=G H G_{\text {Emission }} \times G W P
$$

where $E_{\mathrm{CO}_{2} \text { eq. }}$ is the total amount of greenhouse gases emission from olefin production process ( $\mathrm{tCO}_{2}$-eq.), $G H G_{\text {Emission }}$ is the amount of all greenhouse gases emitted from the process ( $\mathrm{t}$ GHG) and GWP is the value of global warming potential of each greenhouse gases ( $\mathrm{tCO}_{2}$-eq./t GHG)

The evaluation of the greenhouse gas emissions was presented in terms of carbon intensity, which represents the amount of greenhouse gas emission in one unit of olefin produced, as expression in equation (6);

$$
C I=E_{C_{2-} e q .} / P
$$

where $C I$ is carbon intensity of olefins $\left(\mathrm{tCO}_{2}\right.$-eq./ ton of olefin produced), $E_{\mathrm{CO}_{2}-e q}$ is the total amount of greenhouse gas emissions from the process annually ( $\mathrm{tCO}_{2}$-eq./year) and $P$ is the annual olefins production (ton of olefin produced/year).

\section{Results and discussion}

\subsection{Effect of feedstock on El of olefins}

The estimation of energy intensity of olefin production using different types of feedstock was presented. Olefin produced from steam cracking of gas feedstock mostly uses ethane as feedstock, while that steam cracking of liquid feedstock uses only naphtha or mixed with other substances such as ethane, LPG and NGL as feedstock as shown in Figure 2.

An average EI from steam cracking of gas feedstock during 2012-2014 was approximately $23.88 \mathrm{GJ} /$ ton of olefin produced, whilst the average from steam cracking of $30 \%, 80 \%$ and $100 \%$ liquid feedstock were 30.25 , 31.23 and $38.14 \mathrm{GJ} /$ ton of olefin produced respectively. Obviously, the key factor influencing the energy demand for production process is feedstock type. Olefins production using liquid feedstock requires greater amount of energy than using steam cracking of gas feedstock because the more number of carbon atoms in naphtha (512 atoms) absolutely needs the greater energy for breaking down the carbon-carbon bonds of long chain hydrocarbons into the simpler ones than olefins produced from steam cracking of ethane which consists of only 2 carbon atoms. Moreover, using steam cracking of liquid feedstock requires devices in separating process to separate the product and its by-product [8]. Consequently, the energy demand of electricity increased for such the process. Comparing the energy demand through energy intensity varied in portion of liquid feedstock, operating of $80 \%$ liquid feedstock consumed higher energy about $3 \%$ than that of $30 \%$ liquid feedstock, while using $100 \%$ liquid feedstock required greater amount of energy than operating of $80 \%$ liquid feedstock around $22 \%$.

Olefins production requires direct energy consumption from $86-97 \%$ of the total amount of energy, which is higher than the use of indirect energy (3-24\%) as shown in Figure 3, because the use of direct energy mainly contribute for heat raising and cracking process while using indirect energy for any supplement processes. IDB studied greenhouse gas emission from new petrochemical plants reported that the requirement of fossil fuel, steam and power for producing olefins were approximately $60 \%, 35 \%$ and $5 \%$ respectively [6].

\subsection{Effect of feedstock on $\mathrm{Cl}$ for olefins plants}

As shown in Figure 4, carbon intensity of olefins production using gas feedstock was lower than that using 
liquid feedstock. Greenhouse gas emissions during

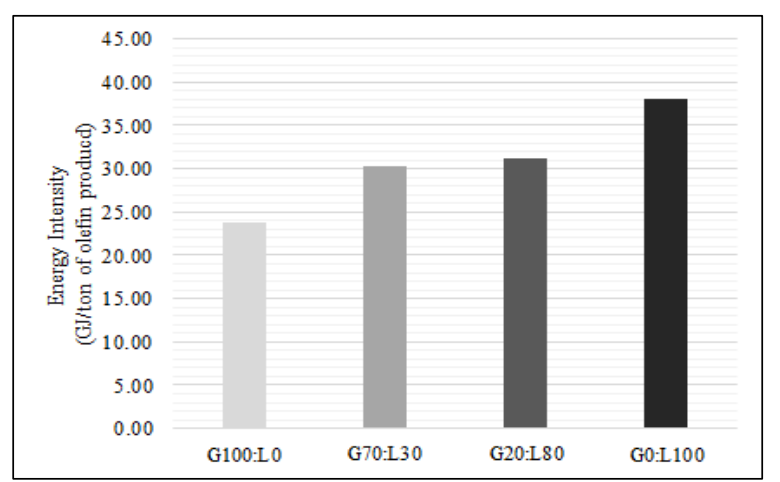

Figure 2. Effect of feedstock types on energy intensity in olefin production process.

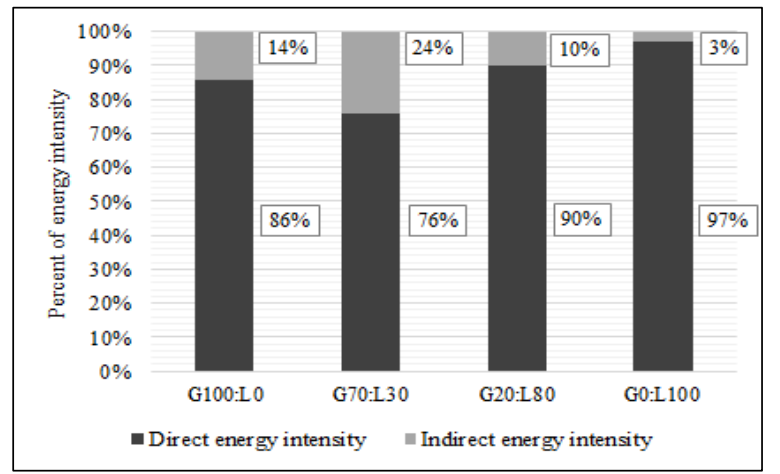

Figure 3. The proportion between direct and indirect energy consumption from the olefin production process.

2012-2014 from olefin production process using gas feedstock had an average of $0.98 \mathrm{tCO}_{2}$-eq./ton of olefin produced, whereas the average emission using steam cracking of $30 \%, 80 \%$ and $100 \%$ liquid feedstock were $1.77,1.75$ and $2.52 \mathrm{tCO}_{2}$-eq./ton of olefin produced respectively. Similar to the result of energy consumption, steam cracking of liquid feedstock (i.e. naphtha) which contents more number of carbon atoms emitted greater emissions than using gas feedstock. Moreover, using liquid feedstock gives the yield of ethylene (30\%) less than using gas feedstock (80\%) [8]. Therefore, different type of feedstock obviously have an effect on different carbon intensity of olefin produced.

In addition, the type of fuel used in the process were regarded as another important factors as it had influenced on CI of olefins. Using fuel oil for combustion process resulted in greater emissions than using only fuel gas because the coefficient of greenhouse gas emission of fuel oil is higher the coefficient of fuel gas. Therefore, the plants consumed mixed fuel (fuel oil with fuel gas) provide higher EI than that operating with fuel gas solely.

As shown in Table 2, it was clearly confirmed that different types of fuel and feedstock affect the energy demand and the greenhouse gas emissions from olefin production process. On the one hand, steam cracking of liquid feedstock provides greater value of EI and CI than that of gas feedstock for all types of fuel; on the other hand, using mixed fuel gives higher point of EI and CI than using single fuel for both feedstock types. For that reason, producing olefins via steam cracking of gas feedstock with fuel gas for combustion process would be an appropriate option both in term of energy and environment.

\subsection{The correlation of $\mathrm{El}$ and $\mathrm{Cl}$ from olefin production}

Olefin production process consumes high energy and emits a large amount of greenhouse gases. According to the analysis of the correlation between energy intensity and the carbon intensity via T-test, it has been found that carbon intensity and energy intensity has a positive correlation significantly $(\mathrm{r}=0.9564$ and $\mathrm{p}=0.05)$. Furthermore, their relationship could be explained by the linear regression with $\mathrm{R}^{2}$ of 0.9147 as shown in the Figure 5.

\subsection{Comparison of energy intensity and carbon intensity with other research}

A comparison of energy intensity and carbon intensity from olefin production in Thailand with other research is shown in Table 3 and Table 4. Based on types of feedstock, the energy demand of olefins from our finding was a bit higher than the result reported by other researchers, which meant there probably are some possibilities for increasing the energy efficiency used in upstream petrochemical industry. Note that, the findings of other research accounted for best practice technology (e.g., catalytic cracking process), which was not the same technology studied in this research.

Generally, the carbon intensity of our findings was the emissions from steam cracking of gas feedstock in this study was slightly less than the value reported by IPPC [13]. It might be because olefin plants in Thailand used cleaner energy (e.g., natural gas) for combustion process, while IPCC reported the average worldwide emissions that used a various kind of fuel.

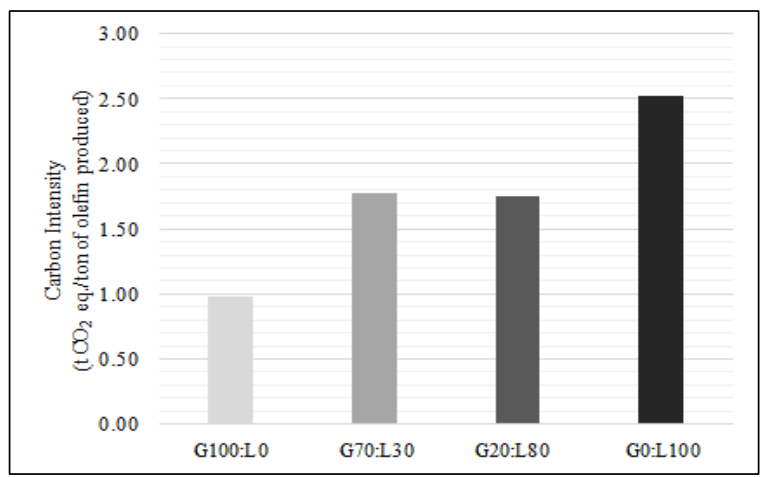

Figure 4. An average carbon intensity of olefin production in Thailand.

Table 2. Comparison of EI and CI of olefin produced from different types of fuel.

\begin{tabular}{ccccc}
\hline \multirow{2}{*}{ FG:FO } & \multicolumn{2}{c}{ Gas feedstock } & \multicolumn{2}{c}{ Liquid feedstock } \\
\cline { 2 - 5 } & $100: 0$ & $90: 10$ & $100: 0$ & $80: 20$ \\
\hline EI & 21.04 & 26.71 & 30.74 & 38.14 \\
\hline
\end{tabular}




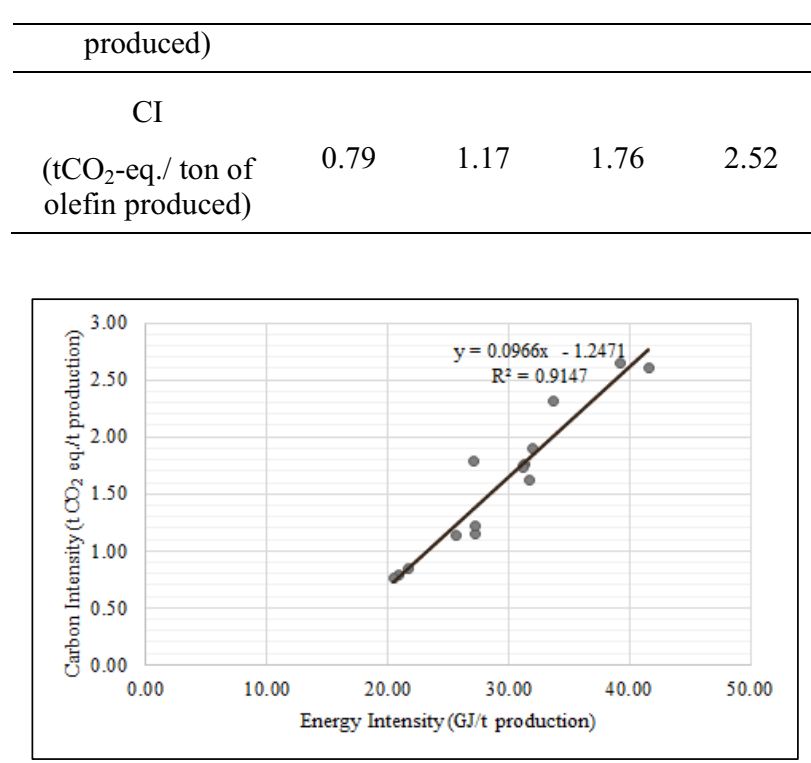

Figure 5. Correlation between energy intensity and the carbon intensity.

Table 3. A Comparison of energy intensity.

\begin{tabular}{|c|c|c|c|}
\hline \multirow{2}{*}{ Feedstock type } & \multirow{2}{*}{ Research } & \multicolumn{2}{|c|}{ Source } \\
\hline & & [8] & [15] \\
\hline Gas & 23.88 & $\begin{array}{l}17.00- \\
21.00\end{array}$ & 16.00 \\
\hline Liquid 30\% & 30.25 & \multirow{3}{*}{$\begin{array}{c}26.00- \\
31.00\end{array}$} & \multirow{3}{*}{16.50} \\
\hline Liquid $80 \%$ & 31.23 & & \\
\hline Liquid 100\% & 38.14 & & \\
\hline
\end{tabular}

Table 4. A comparison of carbon intensity.

\begin{tabular}{|c|c|c|c|}
\hline \multirow{2}{*}{ Feedstock type } & \multirow{2}{*}{ Research } & \multicolumn{2}{|c|}{ Source } \\
\hline & & [13] & [16] \\
\hline Gas & 0.98 & 1.385 & 0.950 \\
\hline Liquid 30\% & 1.77 & \multirow{3}{*}{2.324} & \multirow{3}{*}{1.730} \\
\hline Liquid $80 \%$ & 1.75 & & \\
\hline Liquid 100\% & 2.52 & & \\
\hline
\end{tabular}

\section{Conclusion}

This research is aimed at estimating the energy intensity and carbon intensity from olefins production in Thailand. The annual data was collected from five olefin plants for three years (2012-2014). Our findings illustrated that olefins production via steam cracking of liquid feedstock consumed a larger amount of energy and emitted greater greenhouse gas emissions than that using gas feedstock.
Olefins production required direct energy rather than indirect energy because it was used in combustion process for cracking carbon-carbon bonds. A majority of greenhouse gas emissions from olefin production was accounted to direct emissions mostly produced by fuel combustion process as well. The combustion process with a single type of fuel consumed less energy for heat raising and molecules cracking than that using mixed fuel. The correlation analysis of energy and carbon intensity via $\mathrm{T}$ test clearly confirmed that energy demand for producing olefins in term of EI had a positive correlation significantly with its greenhouse gas emissions in term of $\mathrm{CI}(\mathrm{r}=0.9564$ and $\mathrm{P}=0.05)$. In conclusion, either type of feedstock or fuel have influenced on both energy and carbon intensity of olefins. Recommendation for new olefin plants or improving existing plants, therefore, would be supporting a plant using steam cracking of gas feedstock with a single clean fuel for combustion process which will be beneficial both in term of energy and environment.

\section{Acknowledgement}

This research has been supported by National Research University Project, Office of Higher Education Commission (WCU-58-020-CC)

\section{References}

1. N.N.N. Ahmad, Procedia Soc. Behav. Sci., 172 (2015)

2. S. Zeng, Y. Lan, J. Huang, Int. J. Greenh. Gas Control, 3 (2009)

3. UNFCCC, Conference of the Parties Twenty-first session, (2015)

4. IEA, Worldwide Trends in Energy Use and Efficiency, (2008)

5. K.A. Baumert, T. Herzog, J. Pershing, Navigating the Numbers Greenhouse Gas Data and International Climate Policy, (2005)

6. T. Benchaita, Greenhouse gas Emission from New Petrochemical Plants, (2013)

7. DEDE, A Study on Energy Efficiency Index in petrochemical Industry, (2007)

8. T. Ren, M. Patel, K. Blok, Energy, 31 (2006)

9. E. Worrell, D. Phylipsen, D. Einstein, N. Martin, Energy use and energy intensity of the U.S. chemical industry, (2000)

10.P. Suding, Chemical Plant GHG Emission, (2013)

11.Y.F. Huang, Y.C. Lin, J.T. Yang, Energy Policy, 38 (2010)

12.IEA, Energy Technology Perspectives, (2015)

13. IPCC, Guidelines for National Greenhouse Gas Inventories, Volume 3, (2006)

14. API, Compendium of greenhouse gas emissions methodologies for the oil and natural gas industry, (2009)

15.IEA, Energy and GHG Reductions in the Chemical Industry via Catalytic processes, (2013)

16. M. Neelis, M. Patel, K. Blok, W. Haije, P. Bach, Energy, 32 (2006) 